\title{
Novel strategy of stents in thyroid mass: a case series report of managing severely dyspneic patients
}

\author{
Adheesh Bhandari* \\ Ying-hao Wang* \\ Shi-xu Lv \\ Er-jie Xia \\ Ou-Chen Wang
}

Department of Oncology, The First Affiliated Hospital of Wenzhou

Medical University, Wenzhou, Zhejiang,

People's Republic of China

*These authors contributed equally to this work
This article was published in the following Dove Press journal:

OncoTargets and Therapy

16 October 2017

Number of times this article has been viewed

Background: Tracheal and bronchial stenosis is a life-threatening condition causing difficulty in breathing and even severe respiratory distress. The silicone tracheobronchial stents were placed using the rigid bronchoscopy into the trachea of severe dyspneic patients and they exhibited symptomatic improvement as well as a rise in the saturation of oxygen. The bronchial stents were applicable to many extensive malignant airway stenosis patients, such as those with esophageal cancer, lung cancer, and laryngeal cancer. But the effectiveness of bronchial stents for thyroid cancer is not certain.

Case presentation: Here, we report 3 emergency patients with a thyroid mass referred to our hospital because of grade 4 dyspnea according to the American Thoracic Society shortness of breath guidelines. The main clinical symptoms were severe dyspnea and stridor. The radiographic examination and tomographic examination showed the narrowing and displacement of the trachea. To the best of our knowledge, ideal airway management for the massive thyroid mass was considered to be temporary tracheobronchial stent placement pre-operation.

Conclusion: In our study, we applied the tracheobronchial stent to massive thyroid mass patients with dyspnea and aimed to not only improve preoperative airway obstruction but also to protect the potential airway collapse from post-operative tracheomalacia following extubation. We found that application of tracheobronchial stents may provide a new strategy to dyspneic patients with huge thyroid mass.

Keywords: tracheobronchial stents, airway management, tracheal stenosis, dyspnea

\section{Background}

Significant airway obstruction resulting in severe respiratory distress requires immediate action to promptly regain the airway passage. ${ }^{1}$ Thyroid diseases are more common in females than in males. Usually, the commonest cause for thyroid mass is multinodular goiter or carcinoma of the thyroid gland. An enlarged thyroid mass can induce tracheal obstruction and extraluminal or intraluminal invasion or both. There are a lot of reasons for a tracheal obstruction; the most common reason is that adjacent tumors metastasize or compress the trachea. ${ }^{2}$ Tumor that is adjacent to the airway outside the thorax can compress the upper respiratory tract and induce obstruction, particularly in thyroid cancer. ${ }^{3}$ Due to enlargement of such masses, the tracheobronchial pathway gets compromised. Airway stenosis can be categorized as the following: intraluminal obstruction, extrinsic compression, and malacia (Figure 1, Table 1). ${ }^{3,4}$ Hence, airway stents are employed in these patients before undergoing surgery.

Airway stents, which are tube-shaped devices and are the most common tracheobronchial prosthesis, can be inserted into an airway. They are usually placed by
Correspondence: Ou-Chen Wang Department of Oncology, The First Affiliated Hospital of Wenzhou Medical University, Nanbai Xiang, Ouhai, Wenzhou City, 325000, Zhejiang, People's Republic of China Tel +86 I395770 6099

Email woc863@hotmail.com 


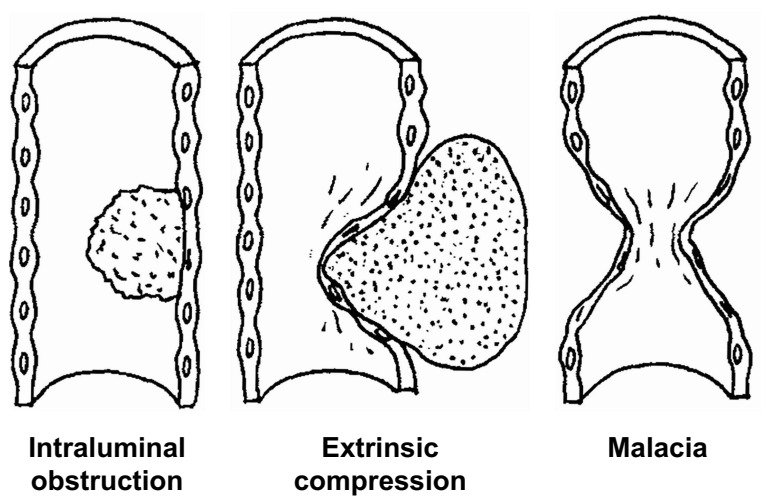

Figure I Classification of the stenosing airway disease by the type of airway involvement.

bronchoscopy and can be applied to deal with problems that appear in a large number of upper airway diseases. ${ }^{4}$ There are protuberances on the external surface of cylindrical Dumon stents, which can help to fix to tracheal mucosa. ${ }^{5,6}$ There are many benefits, such as ease of removal and low reactivity. ${ }^{7}$ But it still has certain drawbacks: it can impair the mucociliary function, which is difficult to fix in certain situations; in some patients with tracheomalacia or conic stenosis, migration of the stent is relatively common; the disadvantageous relationship between the external and internal diameters can induce airway obstruction. ${ }^{5,7}$ Although airway stents have these shortcomings, they have been widely used and have been shown to provide satisfactory results. ${ }^{7,8}$ When airway obstruction is caused by extraluminal compression and/or dynamic collapse, metal and silicone rubber prosthetic stents may stabilize the affected airway. ${ }^{9}$

On examining the pros and cons of metallic stents and silicone stents, it was found that silicone stents are well tolerated, effective, easier to remove without any severe complications (ie, hemorrhage), and relatively easier to insert. Our study presented the primary stent insertion procedure to relieve dyspnea followed by operation and subsequent stent removal.

Table I Type of airway stenosis and treatment of choice

\begin{tabular}{lll}
\hline Type of stenosis & Setting & Treatment of choice \\
\hline $\begin{array}{l}\text { Intrinsic } \\
\text { obstruction }\end{array}$ & Emergent & $\begin{array}{l}\text { Laser ablation, electrocautery, } \\
\text { cryotherapy } \\
\text { Surgical resection, radiation }\end{array}$ \\
Extrinsic & Elective & $\begin{array}{l}\text { Stent insertion } \\
\text { obstruction }\end{array}$ \\
& Emergent & $\begin{array}{l}\text { External radiation, } \\
\text { brachytherapy or operation } \\
\text { (if operable) }\end{array}$ \\
& & Resection and anastomosis \\
Malacia & Operable & Consider stent insertion \\
\hline
\end{tabular}

We present 3 cases of severe tracheal stenosis due to external compression by a massive mass that the application of the Dumon Silicone stents (Novatech, Plan de Grasse, France) aimed at not only improve preoperative airway obstruction but also protect the potential airway collapse from post-operative tracheomalacia.

\section{Case I}

A 60-year-old Chinese female was referred to our hospital with the chief complaints of mass in the neck for 1 year and sudden onset of difficulty in breathing for 1 day. The patient also complained of the change in her voice. She did not have any history of dysphagia, appetite changes, weight changes, or palpitations. She was diagnosed with hypertension for more than 1 year and was under antihypertensive medication. She did not have any history of head or neck irradiation or family history of thyroid disease. On examination, she was conscious, tachypneic (24 breaths/ $\mathrm{min})$, and anxious. Her saturation of oxygen $\left(\mathrm{SpO}_{2} \%\right)$ was 76 . Both inspiration and expiration were shallow and accompanied by a permanent wheeze. A radiograph of the trachea showed severe displacement and narrowing by the thyroid mass. Fiberoptic bronchoscopy was done, which showed a narrowing of the tracheal lumen below the vocal cord as well as deviation of the trachea to the right. The distal airways appeared normal. In addition, other tests were likewise done. Physical examination revealed a mass in the neck, $2 \times 3 \mathrm{~cm}$ of mass on the right side of the neck and $7 \times 6 \mathrm{~cm}$ of mass on the left side of the neck. No enlarged lymph nodes were palpated. Thyroid ultrasound showed diffuse hypoechogenicity and a $5 \times 4 \times 4 \mathrm{~mm}$ hypoechoic nodule on the left side and a $26 \times 14 \times 18 \mathrm{~mm}$ on the right side. It staged the right thyroid mass as TIRADS IVa type and the left thyroid mass as TI-RADS III type. Contrast computed tomography (CT) scan was done, which showed a huge thyroid mass. The patient underwent insertion of the silicone tracheobronchial stent prior to surgery followed by total thyroidectomy and the specimen submitted for histopathological examination revealed follicular adenoma.

\section{Case 2}

A 79-year-old Chinese female presented to the emergency department with rapidly progressive dyspnea, stridor, and dysphagia, which had become worse in the past 10 days. On examination, she was found to be tachypneic, $\mathrm{SpO}_{2} \%$ was 78, and her vital parameters were normal. Spirometry and a flow-volume loop were suggestive of a fixed mixed 
intrathoracic and extrathoracic upper airway obstruction. Fiberoptic bronchoscopy showed the invasion of the trachea by the thyroid mass at $1.5 \mathrm{~cm}$ below the vocal cord and involvement of the bronchus. Her thyroid ultrasound revealed diffuse hypoechogenicity and a $4 \times 3 \mathrm{~mm}$ hypoechoic nodule on the left side. It suggested the thyroid mass as TI-RADS IVb. Contrast CT scan disclosed mass on the left thyroid with calcification and tracheal deviation to the right and stenosis of the trachea. The patient underwent insertion of the tracheobronchial stent prior to surgery and subtotal thyroidectomy. The specimen sent for histopathological examination showed left-sided multinodular goiter with calcification and papillary carcinoma with infiltration in the anterior cervical fibrous tissue.

\section{Case 3}

A 76-year-old Chinese female presented to emergency department with the chief complaints of dyspnea, dizziness, and chest pain for 1 month. The patient did not have any other symptoms such as palpitation, cough, weight changes, and appetite changes. $\mathrm{Her}_{\mathrm{SpO}_{2}} \%$ at the time of admission was 82 . She also had a known case of hypertension. With the use of an antihypertensive drug, her blood pressure was under control. Radiographic examination and tomographic scanning showed tracheal narrowing and displacement. Spirometry and a flowvolume loop were suggestive of a fixed mixed intrathoracic and extrathoracic upper airway obstruction. Fiberoptic bronchoscopy was done, which showed a narrowing of the tracheal lumen below the vocal cord as well as deviation of the trachea to the left. Her thyroid ultrasound revealed diffuse hypoechogenicity and an $11 \times 7 \times 10 \mathrm{~mm}$ hypoechoic nodule on the left side and a $50 \times 33 \times 46 \mathrm{~mm}$ hypoechoic nodule on the right side. It staged the thyroid mass on the right side as TI-RADS II and left side as TI- RADS III. Contrast CT scan disclosed mass on the thyroid with calcification and tracheal deviation to the right and stenosis of the trachea. The patient underwent insertion of the tracheobronchial stent prior to undergoing surgery. The patient then successfully underwent total thyroidectomy. The specimen sent for histopathological examination showed multinodular goiter with hemorrhage and fibrosis.

\section{Materials and methods}

\section{Ethics approval and consent to participate}

This case series report was subject to approval by the Ethics Committee Board of The First Affiliated Hospital of Wenzhou Medical University, Wenzhou, Zhejiang, People's Republic of China.
Written informed consent was provided by the patients for the publication of this case series and accompanying images.

\section{Tracheobronchial stent placement}

All the 3 patients presented to the emergency department with grade 4 dyspnea according to the American Thoracic Society shortness of breath guidelines (Table 2) ${ }^{10}$ Pre-operative airway evaluation revealed Mallampati score class 2, normal thyromental, distance and no limitation of neck or mandible movements, and they all had airway stenosis grade III lesions $71 \%-99 \%$ obstruction according to the classification by Myer-Cotton grading. ${ }^{11}$

The emphasis of anesthesia was focused on airway management strategies for these patients, intended at relieving airway obstruction perioperation. Routine airway management such as endotracheal intubation and laryngeal airway mask was challenging for these patients as the narrowest part of the trachea lay beneath the sternum (Figure 2). Tracheostomy is not practicable if tracheal obstruction has occurred. Therefore, after careful consideration and discussion with the surgeons and anesthesiologist, the placement of a tracheobronchial stent under topical anesthesia was the first choice for airway obstruction management. Further, tracheobronchial stent helps to prevent a devastating situation that might occur during induction of anesthesia. Relaxation of airway smooth muscle with anesthetic agents can further compress the airways, followed by inability of ventilation for these patients.

For the placement of a tracheal stent, the patient was given topical anesthesia. Then, through the help of the rigid bronchoscope, the silicone stent was placed (Figure 3). Muscle relaxants are not generally needed. Through the accessory port, ventilation can be administered, but it

Table 2 Hugh-Jones classification for assessment of breathlessness on the basis of daily activities

\begin{tabular}{|c|c|}
\hline Grade & Description \\
\hline 1 & $\begin{array}{l}\text { The patient's breathing is as good as that of others of the } \\
\text { same sex, age, and build while at work, on walking, or on } \\
\text { climbing hills or stairs }\end{array}$ \\
\hline 2 & $\begin{array}{l}\text { The patient is able to walk with healthy persons of the same } \\
\text { sex, age, and build on ground level but is unable to keep up on } \\
\text { hills or stairs }\end{array}$ \\
\hline 3 & $\begin{array}{l}\text { The patient is unable to keep up with healthy persons on } \\
\text { ground level but is able to walk a mile or more at a slow speed }\end{array}$ \\
\hline 4 & $\begin{array}{l}\text { The patient is unable to walk more than } 100 \text { yards on ground } \\
\text { level without a rest }\end{array}$ \\
\hline 5 & $\begin{array}{l}\text { The patient is breathless on talking or undressing or is unable } \\
\text { to leave the house because of breathlessness }\end{array}$ \\
\hline
\end{tabular}



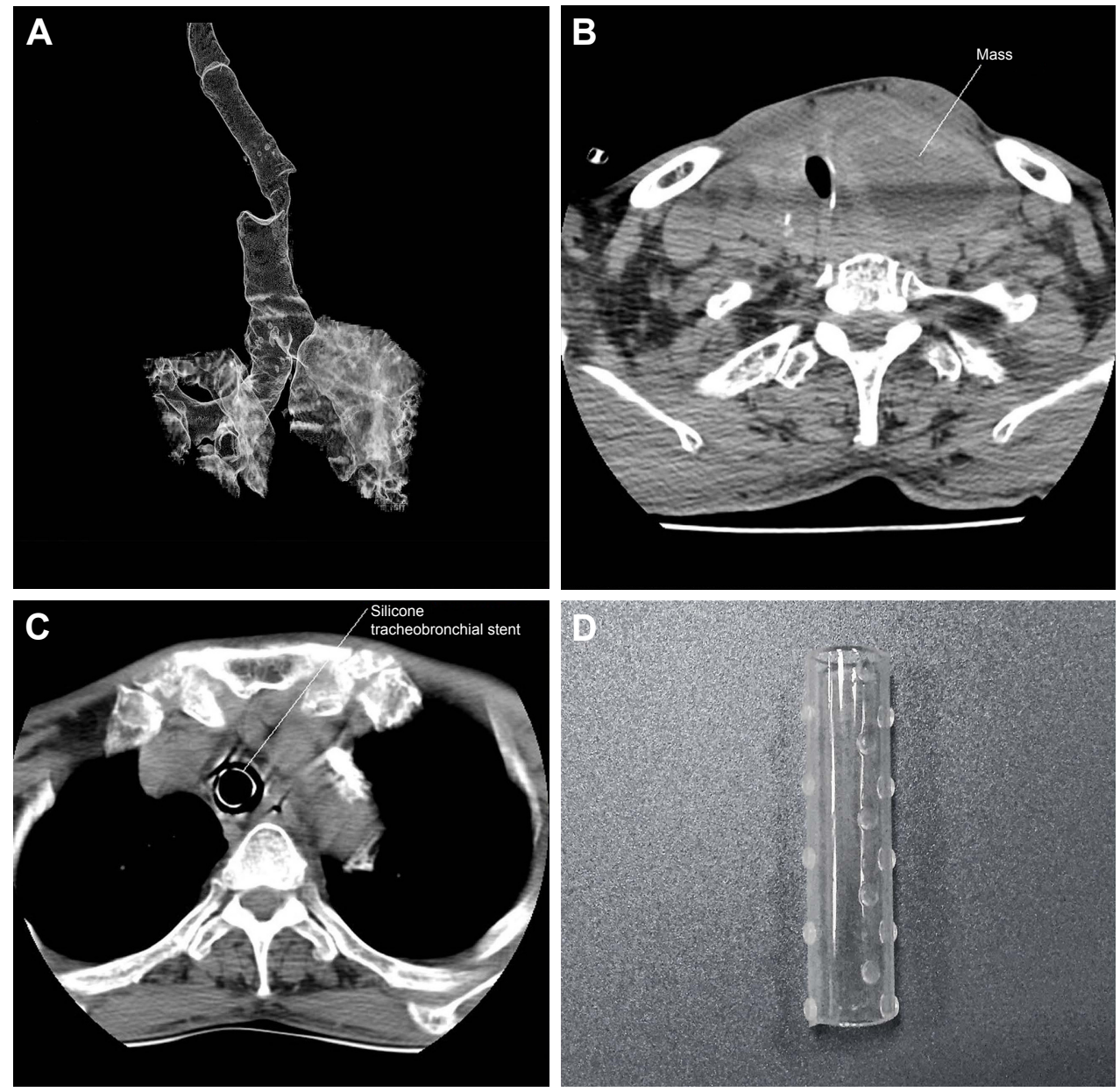

Figure 2 (A) Three-dimensional computed tomography (CT) scan showed the narrowest part of the trachea present beneath the sternum. (B) Axial CT scan was done. A mass can be seen on the right side of the trachea, and due to the mass the trachea is deviated to the left side, compromising the airway tract before placement of the tracheobronchial stent. (C) After the placement of the tracheobronchial stent, the airway was recovered. (D) Dumon Silicone stent.

may add complications without evident benefits. Before inserting the rigid bronchoscope, topical anesthetic should be managed, and topical anesthesia is instilled through a laryngeal syringe in the upper airway. During the process, additional topical anesthetic is administered to prevent cough reflex. Propofol $(2.0 \mathrm{mg} / \mathrm{kg})$ and fentanyl $(2.5 \mu \mathrm{g} / \mathrm{kg})$ are the drugs of choice to induce anesthesia, and propofol $(7-8 \mathrm{mg} / \mathrm{kg} / \mathrm{h}$ reduced to $5-6 \mathrm{mg} / \mathrm{kg} / \mathrm{h}$ after $15 \mathrm{~min})$ is used to maintain the anesthesia. After the placement of a stent, CT scan was recommended to the patient to see the placement of the stent (Figure 2). $\mathrm{SpO}_{2} \%$ was significantly improved (Figure 4).

After tracheobronchial stent placement, thyroidectomy was planned. During the time of operation, standard monitoring including blood pressure cuff, electrocardiogram leads, a pulse oximeter to monitor $\mathrm{SpO}_{2} \%$, and end tidal carbon dioxide was placed in position. Midazolam $2 \mathrm{mg}$, fentanyl $0.3 \mathrm{mg}$, vecuronium $8 \mathrm{mg}$, and propofol $120 \mathrm{mg}$, were used to induce anesthesia; a reinforced endotracheal tube (ETT) with an inner diameter of $6.5 \mathrm{~mm}$ was inserted under fibroscopic guidance. The surgical procedure was successful. The ventilator was weaned off 10-20 mins after the surgical procedure and then the patients were extubated as their consciousness recovered. The patients were managed in the post-anesthesia care unit (PACU). They were then sent to the ward after the vital parameters were found to be normal and $\mathrm{SpO}_{2} \%$ maintained around $96 \%$ at PACU. The patients were discharged from the hospital a few days after recovery and the tracheobronchial stent was removed without any further complications.

\section{Discussion}

The airway stenosis may cause obstructive clinical symptoms; a mild symptom may be shortness of breath, and a severe symptom would be suffocation. Anesthesia management of the huge cervicomediastinal goiter patients always 

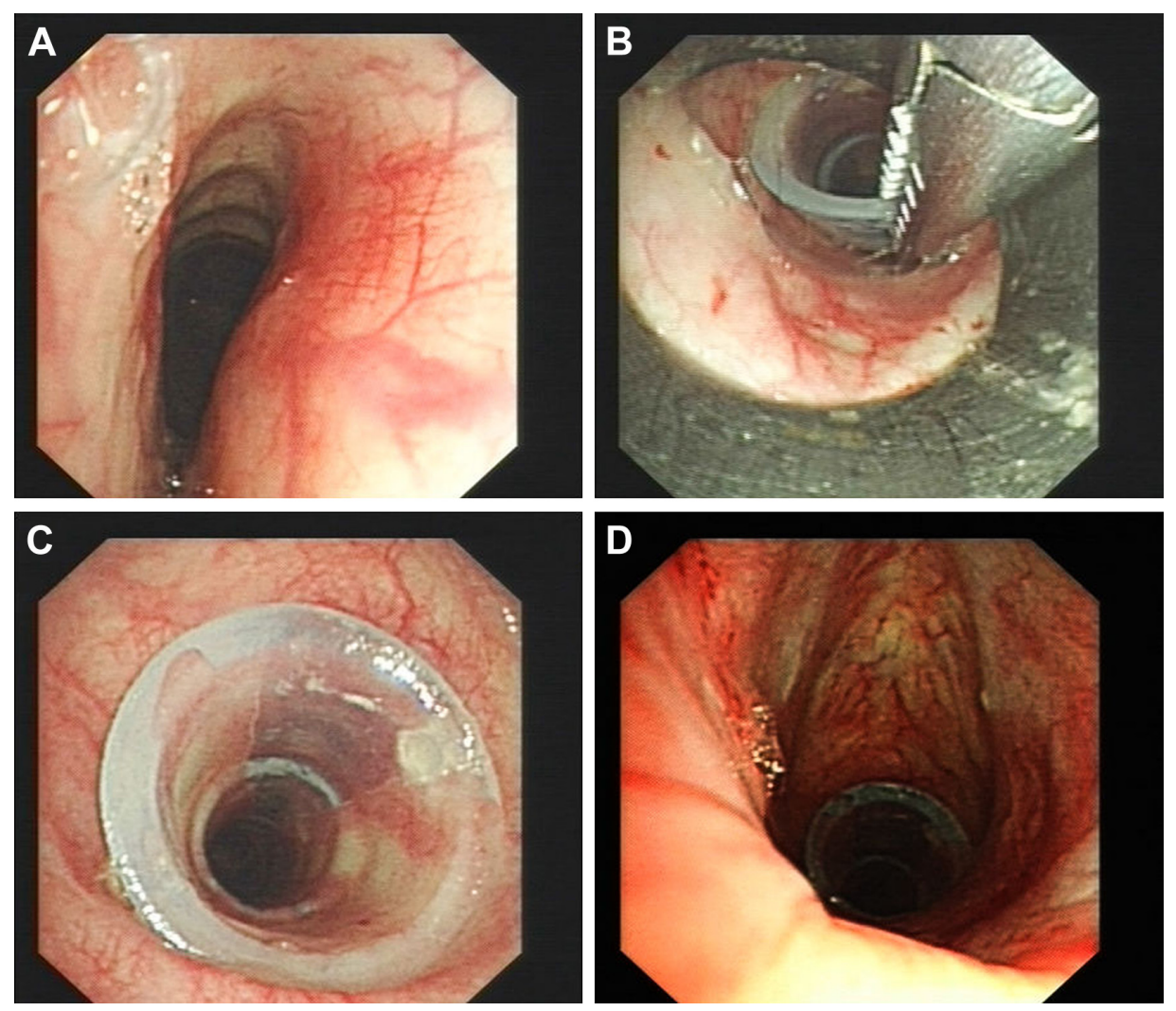

Figure 3 Bronchoscopic examination through the nose $(\mathbf{A})$ showed that the trachea was depressed. (B) Silicone tracheobronchial stent of diameter $16 \times 14 \times 16$ mm and length $15 \times 20 \times 15 \mathrm{~mm}$ was placed with the help of the bronchoscope. (C) Tracheobronchial stent placed on stenosed trachea site. (D) Final image after placement of the tracheobronchial stent.

gives anesthesiologists additional challenges, such as tracheal collapse after extubation. Based on the location of the tracheal stenosis and its severity, perioperative airway management may have multiple options, such as masks, endotracheal intubation, ${ }^{12,13}$ tracheotomy, laryngeal airway mask, ${ }^{12}$ extracorporeal membrane oxygenation (ECMO), and cardiopulmonary bypass. ${ }^{14}$ The above-mentioned procedures seemed unsuitable for our patients. After consultations with anesthesiologists and surgeons, the decision to place a temporary tracheobronchial stent under topical anesthesia with the help of the rigid bronchoscope was planned and then thyroidectomy was performed with reinforced ETT intubation under general anesthesia. In patients with a substernal thyroid mass, the anesthetic considerations may differ depending on the surgical procedure proposed, anatomy, and pathology.

In some situations, substernal goiter can induce severe tracheal stenosis and even cause a life-threatening complication; total airway obstruction. In general, because more than $50 \%$ of its volume is located below the thoracic inlet, this kind of thyroid mass is named as substernal goiter. ${ }^{15}$ However, retrosternal is probably a more precise term to describe this situation. When the tracheal diameter is less than $8 \mathrm{~mm}$, exertional dyspnea is the most common airway obstructive symptom, accounting for $30 \%-60 \%$ in all cases. But there are still some patients with invasive thyroid cancer, and CT scanning is just an efficient approach to find distant and regional metastasis. While magnetic resonance imaging is an effective way to find cervical lymph node metastasis, its function to characterize thyroid nodules is limited. ${ }^{16}$

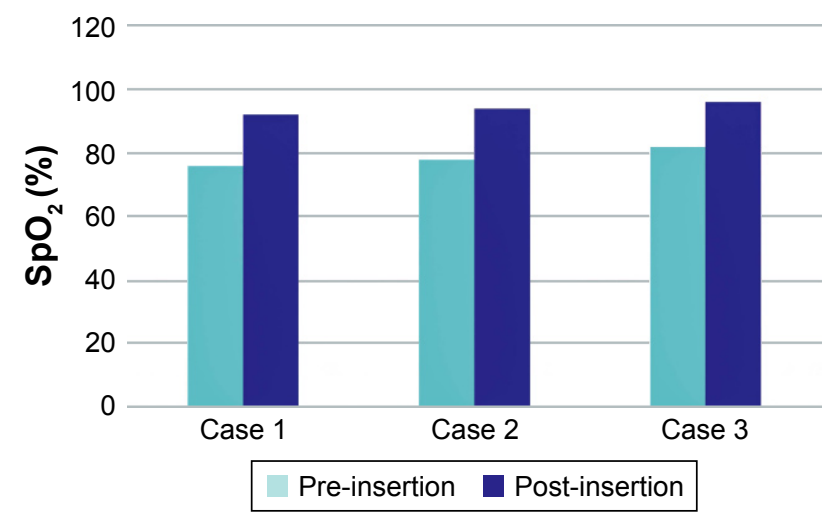

Figure 4 Improvement of oxygen saturation value (pre-insertion and postinsertion). 
Tracheobronchial stenosis by neoplastic or non-neoplastic processes may be focal (caused by post-intubation tracheal stenosis) or may be diffuse (caused by inflammation). When narrowing obstructs airflow and increases resistance in the airway, the symptoms usually develop. The extent and severity of the disease can be determined by CT; the treatment algorithm can be devised with the help of endoscopy. Bronchoscopic interventions have many choices, including ablative treatment, balloons, and stenting to provide symptomatic relief. Surgical resection may be an approach that is curative and multidisciplinary to tracheobronchial stenosis. ${ }^{17}$

Compared with adult patients, the effect of the stent in pediatric patients is worse than in adult patients. Pediatric patients, because issues of pulmonary and trachea of pediatric patients grow gradually, inducing that a stent removes and replace ${ }^{14}$ Generally, the most common indication is malignant stenosis, although stents can be applied in both benign and malignant airway management. ${ }^{18,19}$

For severe airway obstruction, a tracheobronchial stent is an option that is considered as minimally invasive therapy. Metal stents are radiopaque and thus are usually used in the radiological suite; silicone stents are radiolucent, nonexpandable, require some type of affixation, and thus are used in the operating rooms. Stent complications more likely appear in long-term treatment benign conditions. The use of endoscopy for removal of stents is successful and safe without any complications when a metallic stent is in place for a long time, there is difficulty in removing it. ${ }^{20}$ The removal of the metallic stent can be done either through an external open method or by the destruction of the stent and piecemeal removal of the wires endoscopically. Over the last few years, death has been reported during metallic stent removal. Compared with metallic stents, silicone stents are easier to adjust and remove. When it is necessary, silicone stents can be repositioned and changed many times. Besides, there is no reaction of the airway mucosa and no ingrowth with silicone stents. In our patients, we used the Dumon Silicone stent (Novatech, Plan de Grasse, France) (Figure 2), which has a cylindrical form. The outer surface of the stent has studs, which prevent shifting as well as restrict contact with airway wall to minimize mucosal ischemia. These stents provide a vault effect of even distribution and thus preserve clearance of secretions. Dumon Silicone stents are available in various sizes and diameters that range from 20 to $90 \mathrm{~mm}$ in length and 9 to $18 \mathrm{~mm}$ in the external diameter. Thus, the silicone stents can be restricted to the narrow area in an airway. The rims of the stents are polished in order to decrease the chances of granuloma formation. In order to improve the visualization on chest X-ray, we can also use radiopaque Dumon stents. The main disadvantage of these stents is that placement needs rigid bronchoscopy and their removal is not easy. One of the other drawbacks of the stent is that the thicker wall inducing its smaller inner diameter could cause dislodgement and distortion. In most of the cases, airway stents are applied for relieving the condition of patients with malignant airway obstruction. There are many diseases that induce airway obstruction such as thyroid carcinoma, esophageal cancer, lung cancer, and lymphoma, which are so severe that they are not suitable for bronchoscopic or surgical repair. ${ }^{21,22}$ Application of endoluminal stent provides an effective and rapid approach of airway patency, thereby dramatically improving pulmonary function and symptoms. ${ }^{23}$ It has been reported that the condition of dangerous dyspnea in $70 \%-100 \%$ of patients with airway stenosis can be relieved rapidly after placing the tracheobronchial stent, ${ }^{24}$ which will help doctors to decide to perform this surgery more often. However, it is in up to $42 \%$ of patients that stent complications have been reported. There are long-term complications including migration (17\%), mucostasis causing airway obstruction (6\%), and granuloma $(6 \%) .{ }^{25}$ A study found that $42 \%$ of patients even need extra emergency bronchoscopy for complications relating to stent insertion within 3 months. ${ }^{26}$ Besides, occurrence of local inflammatory reaction leads to the growth of granulation tissue. Symptoms of granulation tissue formation may vary in different patients. Some patients' granulation tissue is mild enough to remain asymptomatic and some granulation is moderate and produces stridor, but some patients' granulation is severe enough to produce life-threatening respiratory distress. ${ }^{27}$ Therefore, covered stents are being introduced in the market, which can prevent granulation tissue or tumor to proliferate through the stent. However, the disadvantage of covered stents is the existence of a covering hampering sputum expectoration and thus increasing the possibility of infection. Although uncovered stents do not increase the likelihood of respiratory infection, they allow granulation tissue to proliferate within the stent and block its lumen and cause difficulties in removing the stent. Laser resection of in-stent granuloma must be performed with caution by skilled surgeons because there have been reports of stent damage. ${ }^{28}$ Intubation may result in endotracheal edema in the patient as repeated attempts for the ETT passing through the stenosis are inevitable. In the aforementioned patients, even mild edema could lead to airway obstruction, which can be life threatening. We should choose correct ETT, as usual ETT (7.0-8.0 mm ID for adult) for intubation whose 
narrowest caliber of the stenotic trachea was $3.0 \mathrm{~mm}$ in diameter nor should we choose a thinner ETT which is insufficient for ventilation.

The day of surgery, ETT intubation was placed under the guidance of fiberscope to avoid malposition or migration of the tracheobronchial stent. The patients were called for follow-up checkup to prevent any formation of granulation tissue and to avoid further complications due to the placement of a tracheobronchial stent. No complications were found after the removal of the tracheobronchial stent.

As mentioned earlier, tracheobronchial stent placement may be the ideal choice for the patient and to protect the trachea from potential collapse due to tracheomalacia by a huge thyroid mass following extubation.

\section{Conclusion}

We conclude that the pre-operative placement of the tracheobronchial stent is a viable option for the airway management in massive thyroid mass prior to resection. It plays a vital role to relieve dyspnea caused by in-growing thyroid masses. For severe tracheal stenosis by massive thyroid masses, the placing stent with acceptable complications is a feasible choice particularly for those patients who need operation and resection, this management may be the last resort or even desirable solution to keep airway stability no matter in short term or long term.

\section{Availability of data and materials}

The datasets supporting the conclusions of this article are included within this article and its additional images. Raw data are available in the main electronic data storage system of The First Affiliated Hospital of Wenzhou Medical University and access can be provided upon request to the authors.

\section{Acknowledgments}

The authors would like to thank all the doctors of the Respiratory Department and Radiology Department of The First Affiliated Hospital of Wenzhou Medical University for providing all the images and necessary information required for our case series report. Without their help, this article would not have been possible. This study was supported by the Key Project of Science and Technology Innovation Team of Zhejiang Province (2013TD10) and National Natural Science Foundation of China (Number 81372380).

\section{Disclosure}

The authors report no conflicts of interest in this work.

\section{References}

1. Bolliger CT, Mathur PN, Beamis JF, et al; European Respiratory Society/American Thoracic Society. ERS/ATS statement on interventional pulmonology. European Respiratory Society/American Thoracic Society. Eur Respir J. 2002;19(2):356-373.

2. Wood DE. Management of malignant tracheobronchial obstruction. Surg Clin North Am. 2002;82(3):621-642.

3. Utz JP, Prakash UBS. Indications for and contraindications to bronchoscopy. In: Prakash UBS, editor. Bronchoscopy. 1st ed. New York: Raven Press; 1994:81-89.

4. Colt HG, Dumon JF. Airway stents. Present and future. Clin Chest Med. 1995;16(3):465-478.

5. Dumon JF. A dedicated tracheobronchial stent. Chest. 1990;97(2): 328-332.

6. Dumon JF, Reboud E, Garbe L, Aucomte F, Meric B. Treatment of tracheobronchial lesions by laser photoresection. Chest. 1982;81(3): 278-284.

7. Bolliger CT, Probst R, Tschopp K, Solèr M, Perruchoud AP. Silicone stents in the management of inoperable tracheobronchial stenoses. Indications and limitations. Chest. 1993;104(6):1653-1659.

8. Cavaliere S, Venuta F, Foccoli P, Toninelli C, La Face B. Endoscopic treatment of malignant airway obstructions in 2,008 patients. Chest. 1996;110(6):1536-1542.

9. Gelb AF, Zamel N, Colchen A, et al. Physiologic studies of tracheobronchial stents in airway obstruction. Am Rev Respir Dis. 1992;146(4): 1088-1090.

10. Hugh-Jones $P$, Lambert AV. A simple standard exercise test and its use for measuring exertion dyspnoea. Br Med J. 1952;1(4749):65-71.

11. Myer CM 3rd, O'Connor DM, Cotton RT. Proposed grading system for subglottic stenosis based on endotracheal tube sizes. Ann Otol Rhinol Laryngol. 1994;103(4 Pt 1):319-323.

12. Asai T, Shingu K. Airway management of a patient with tracheal stenosis for surgery in the prone position. Can J Anaesth. 2004;51(7): 733-736.

13. CookTM, Seller C, Gupta K, Thornton M, O'Sullivan E. Non-conventional uses of the Aintree Intubating Catheter in management of the difficult airway. Anaesthesia. 2007;62(2):169-174.

14. Asai T. Emergency cardiopulmonary bypass in a patient with a mediastinal mass. Anaesthesia. 2007;62(8):859-860.

15. Hardy RG, Bliss RD, Lennard TW, Balasubramanian SP, Harrison BJ. Management of retrosternal goitres. Ann R Coll Surg Engl. 2009; 91(1):8-11.

16. Bruneton JN, Balu-Maestro C, Marcy PY, Melia P, Mourou MY. Very high frequency (13 MHz) ultrasonographic examination of the normal neck: detection of normal lymph nodes and thyroid nodules. $J$ Ultrasound Med. 1994;13(2):87-90.

17. Puchalski J, Musani AI. Tracheobronchial stenosis: causes and advances in management. Clin Chest Med. 2013;34(3):557-567.

18. Furukawa K, Ishida J, Yamaguchi G, et al. The role of airway stent placement in the management of tracheobronchial stenosis caused by inoperable advanced lung cancer. Surg Today. 2010;40(4):315-320.

19. Walser EM. Stent placement for tracheobronchial disease. Eur J Radiol. 2005;55(3):321-330.

20. Zakaluzny SA, Lane JD, Mair EA. Complications of tracheobronchial airway stents. Otolaryngol Head Neck Surg. 2003;128(4):478-488.

21. Rafanan AL, Mehta AC. Stenting of the tracheobronchial tree. Radiol Clin North Am. 2000;38(2):395-408.

22. Rajeev P, Ezzat T, Slade M, Sadler GP, Mihai R. Tracheal stenting has minimal impact on survival in anaplastic thyroid carcinoma. World $J$ Surg. 2013;37(11):2589-2593.

23. Mostafa BE, Dessouky OY. The role of endoluminal self-expanding stents in the management of pediatric tracheal stenosis. Int J Pediatr Otorhinolaryngol. 2008;72(9):1371-1376.

24. Saad CP, Murthy S, Krizmanich G, Mehta AC. Self-expandable metallic airway stents and flexible bronchoscopy: long-term outcomes analysis. Chest. 2003;124(5):1993-1999. 
25. Wood DE, Liu YH, Vallières E, Karmy-Jones R, Mulligan MS. Airway stenting for malignant and benign tracheobronchial stenosis. Ann Thorac Surg. 2003;76(1):167-172; discussion 173-174.

26. Matsuo T, Colt HG. Evidence against routine scheduling of surveillance bronchoscopy after stent insertion. Chest. 2000;118(5):1455-1459.
27. Filler RM, Forte V, Chait P. Tracheobronchial stenting for the treatment of airway obstruction. J Pediatr Surg. 1998;33(2):304-311.

28. Gaissert HA, Grillo HC, Wright CD, Donahue DM, Wain JC, Mathisen DJ. Complication of benign tracheobronchial strictures by self-expanding metal stents. J Thorac Cardiovasc Surg. 2003;126(3):744-747.

\section{Publish your work in this journal}

OncoTargets and Therapy is an international, peer-reviewed, open access journal focusing on the pathological basis of all cancers, potential targets for therapy and treatment protocols employed to improve the management of cancer patients. The journal also focuses on the impact of management programs and new therapeutic agents and protocols on

patient perspectives such as quality of life, adherence and satisfaction. The manuscript management system is completely online and includes a very quick and fair peer-review system, which is all easy to use. Visit http://www.dovepress.com/testimonials.php to read real quotes from published authors. 